\title{
Papers
}

\section{Birth weight of offspring and insulin resistance in late adulthood: cross sectional survey}

Debbie A Lawlor, George Davey Smith, Shah Ebrahim

\begin{abstract}
Objective To investigate the association between birth weight of offspring and mothers' insulin resistance in late adulthood.

Design Cross sectional survey.

Setting General practitioner's surgeries in 23 towns in Great Britain.

Participants 4286 women aged 60-79 years.

Main outcome measures Maternal insulin resistance.

Results Birth weight of offspring was inversely related to maternal insulin resistance in late adulthood. For each $1 \mathrm{~kg}$ higher birth weight of offspring, women had a $15 \%$ reduction in the odds of being in the fourth with highest insulin resistance, compared to other fourths (odds ratio $0.85 ; 95 \%$ confidence interval 0.71 to 1.00$)$. This increased to $27 \%(0.73$; 0.60 to 0.90 ) after adjusting data for potential confounders. A U shaped relation between birth weight of offspring and diabetes in older age was found; women with the lightest and heaviest offspring had the highest prevalence of diabetes.

Conclusions Birth weight of offspring is inversely related to the mother's insulin resistance in late adulthood, despite the association of glucose intolerance during pregnancy with heavier offspring at birth. Common genetic factors contribute to the relation between birth weight and risk of cardiovascular disease and diabetes in adults.
\end{abstract}

\section{Introduction}

Low birth weight is associated with cardiovascular disease and type 2 diabetes in adulthood, but the mechanisms underlying these associations are unclear. ${ }^{1}$ Poor intrauterine nutrition leads to babies with low birth weight and may "programme" selective changes in body composition, hormonal axes, and metabolism, leading to increased risk of cardiovascular disease in later life. ${ }^{1}$ Alternatively, the fetal insulin hypothesis suggests that the specific genetic polymorphisms lead to increased insulin resistance and impaired growth and that these polymorphisms underlie the association between birth weight and cardiovascular disease. Studies have shown that low birth weight of offspring is related to an increased risk of cardiovascular disease and diabetes in the parents. ${ }^{3-10}$

The relation between low birth weight and later risk of disease in the individual may be explained by a pro- gramming effect of the intrauterine environment, ${ }^{1}$ but the relation between a baby's low birth weight and its parents' risk must have a different explanation: a plausible explanation for these transgenerational associations is that birth weight and cardiovascular disease are linked by a common genetic factor.

No previous study has directly assessed the fetal insulin hypothesis by looking at the association between birth weight of offspring and parental insulin resistance. Mothers with gestational glucose intolerance tend to have heavier babies, ${ }^{10}$ and since these mothers are more likely to be insulin resistant and to develop diabetes later in life, ${ }^{11}$ the expectation is of a positive correlation between birth weight of offspring and maternal insulin resistance. If an inverse association between birth weight of offspring and parental insulin resistance exists, particularly in mothers, it would support the fetal insulin hypothesis. We investigated the associations between offspring birth weight and maternal insulin resistance in late adulthood.

\section{Participants and methods}

The British women's heart and health study is a sample of 60-79 year old women, randomly selected from general practitioners' lists in 23 towns in Great Britain. We selected towns, general practitioners, and participants in the same way as for the British regional heart study of men. ${ }^{12}$ Of the 7143 women invited, $4286(60 \%)$ participated. We collected baseline data (via questionnaires, interviewing by a research nurse, and examinations) between April 1999 and March 2001. Ethics committee approval was obtained for the British women's heart and health study.

Details of all measurements are published elsewhere. ${ }^{13}$ Participants were asked how many pregnancies and live births they had experienced. We asked women with at least one live birth to provide the sex and birth weight of their first born child. We took fasting blood samples and estimated insulin resistance with the homoeostasis model assessment (the product of fasting glucose and insulin concentrations (in mmol/l) divided by 22.5). ${ }^{14}$ We considered women with a clinical diagnosis of diabetes and women with a fasting glucose concentration of $\geqslant 8 \mathrm{mmol} / 1$ to have diabetes, for the purpose of this study. Homoeostasis model assessment scores are not valid for these women, and were not calculated. ${ }^{14}$
Department of
Social Medicine,
University of
Bristol, Bristol
BS8 2PR
Debbie A Lawlor
MRC research
training fellow
George Davey
Smith
professor of clinical
epidemiology
Shah Ebrahim
professor of
epidemiology of
ageing
Correspondence to:
D A Lawlor
d.a.lawlor@bristol.
ac.uk
bmj.com 2002;325:359 


\section{Statistical analysis}

Because boys are, on average, heavier at birth than girls, we subtracted the difference between the mean male and female birth weights from mean male birth weight. Age adjusted mean scores of insulin resistance (homoeostasis assessment model scores) and the means and prevalence of other risk factors for cardiovascular disease are given with 95\% confidence intervals for each quarter of women, ordered by the birth weight of their offspring. For each of these risk factors, we used multiple linear regression for continuous variables and multiple logistic regression for categorical variables to determine the age adjusted change, resulting from a $1 \mathrm{~kg}$ increase in birth weight of offspring.

We defined participants as having high insulin resistance if they were in the top quarter of homoeostasis model assessment scores. We used multiple logistic regression to estimate the odds of high insulin resistance per $1 \mathrm{~kg}$ change in offspring birth weight with adjustment for potential confounders. Age, body mass index, waist to hip ratio, systolic and diastolic blood pressure, high density lipoprotein cholesterol, low density lipoprotein cholesterol, and triglycerides (logged) were entered as continuous variables in these models. Socioeconomic group (I, II, III non-manual, III manual, IV, or V) and smoking status (never smoked, ex-smoker, or current smoker) were entered as categorical variables. For adults, we allocated socioeconomic groups according to the longest held job of single women and the job of a married woman's husband. The mother's childhood social class was allocated according to her father's longest held job. Two dummy variables representing those with no available socioeconomic group (259 women's adult social class and 180 women's childhood social class).

Homoeostasis model assessment scores and triglyceride concentration were $\log$ normal: geometric means are presented and the natural logs of the score and concentration were used in the regression models.

\section{Results}

Of the 4286 women who participated, 3849 (90\%) provided obstetric details. Of the $3456(90 \%)$ women who had had at least one live birth, 3289 (94\%) provided their firstborn's birth weight. For 24 women, birth weight of offspring was less than $1.5 \mathrm{~kg}$; they were excluded. Of the 3265 women with offspring birth weight included in the analysis 1635 (50.1\%) of the children were male with a mean birth weight of 3.38 (SD 0.53) $\mathrm{kg}$ and 1630 (49.9\%) were female with a mean birth weight of $3.24(0.51) \mathrm{kg}$. A total of 169 $(5.2 \%)$ women had been diagnosed with diabetes by a doctor and $41(1.3 \%)$ had a glucose concentration after fasting of $\geqslant 8 \mathrm{mmol} / \mathrm{l}$.

The table gives the relations between birth weight of offspring and age adjusted insulin resistance scores and other risk factors for cardiovascular disease, together with regression coefficient or odds ratios for each variable per kilogram difference in offspring birth weight. Women who had heavier babies were less resistant to insulin, had lower systolic blood pressure, had a higher body mass index, were less likely to smoke, and were more likely to belong to non-manual social classes both in childhood and adulthood.

Offspring birth weight was not linearly associated with maternal diabetes prevalence; women who had had babies with birth weights in the lowest and highest quarters were most likely to be diabetic in older age. When a quadratic term for birth weight of offspring was fitted, this model suggested a non-linear association $(\mathrm{P}=0.08)$. The relation between diabetes prevalence and birth weight of offspring was unaffected by control for current body mass index. The inverse relation between offspring birth weight and maternal insulin resistance contradicted the positive relation between birth weight of offspring and maternal body mass index. For each increase of $1 \mathrm{~kg}$ to offspring birth weight, the logarithm of the insulin resistance scores fell by 0.04 , whereas body mass index (weight $(\mathrm{kg}) /\left(\right.$ height $\left.(\mathrm{m})^{2}\right)$ increased by 0.74 .

The odds of maternal insulin resistance (top quarter of birth weights compared with all other participants, adjusted by age) decreased with increas-

Relation of maternal characteristics to birth weight of offspring

\begin{tabular}{|c|c|c|c|c|c|c|}
\hline \multirow[b]{2}{*}{ Maternal characteristics } & \multicolumn{4}{|c|}{ Fourth of offspring birth weight $(\mathbf{k g})$} & \multirow{2}{*}{$\begin{array}{l}\text { Age adjusted difference } \\
\text { per kg offspring birth } \\
\text { weight }\end{array}$} & \multirow[b]{2}{*}{$P$ value } \\
\hline & $1.56-2.94$ & $2.95-3.26$ & $3.27-3.58$ & $3.59-4.88$ & & \\
\hline Age (years) & 68.4 (68.1 to 68.8$)$ & 68.4 (68.1 to 68.8$)$ & 68.7 (68.4 to 69.2$)$ & 68.9 (68.6 to 69.4$)$ & $0.48(0.12$ to 0.84$)$ & 0.009 \\
\hline Insulin resistance (HOMA score) ${ }^{\dagger}$ & 1.75 (1.67 to 1.83$)$ & 1.61 (1.54 to 1.69$)$ & 1.67 (1.59 to 1.75$)$ & $1.60(1.53$ to 1.67$)$ & $-0.04(-0.08$ to -0.01$)$ & 0.04 \\
\hline Diabetes $(\%)^{\ddagger}$ & $8.1(6.3$ to 10.3$)$ & 7.5 (5.7 to 9.7$)$ & $6.3(4.7$ to 9.7$)$ & $7.9(6.1$ to 10.1$)$ & 0.93 (0.71 to 1.22$)$ & 0.67 \\
\hline Systolic blood pressure $(\mathrm{mm} \mathrm{Hg})$ & 149.5 (147.8 to 151.2$)$ & 147.3 (145.6 to 149.1$)$ & 145.8 (144.1 to 147.5$)$ & 146.8 (145.1 to 148.5$)$ & $-1.79(-3.42$ to -0.15$)$ & 0.03 \\
\hline $\mathrm{HDLC}(\mathrm{mmol} / \mathrm{l})$ & 1.64 (1.61 to 1.67$)$ & $1.66(1.63$ to 1.69$)$ & 1.68 (1.65 to 1.72) & 1.63 (1.59 to 1.66$)$ & $0.003(-0.03$ to 0.03$)$ & 0.85 \\
\hline LDLc (mmol/l) & 4.17 (4.09 to 4.25$)$ & 4.15 (4.07 to 4.23$)$ & 4.17 (4.09 to 4.25$)$ & 4.15 (4.07 to 4.23$)$ & $-0.03(-0.10$ to 0.05$)$ & 0.49 \\
\hline Triglyceride $(\mathrm{mmol} /)^{\dagger}$ & 1.70 (1.65 to 1.76$)$ & 1.63 (1.58 to 1.68$)$ & 1.65 (1.59 to 1.71$)$ & 1.68 (1.62 to 1.73$)$ & $-0.01(-0.04$ to 0.02$)$ & 0.48 \\
\hline Body mass index $\left(\mathrm{kg} / \mathrm{m}^{2}\right)$ & 27.2 (26.9 to 27.6$)$ & 27.2 (26.9 to 27.6$)$ & 27.6 (27.3 to 28.0$)$ & 28.2 (27.9 to 28.6$)$ & 0.74 (0.41 to 1.07$)$ & $<0.001$ \\
\hline Waist to hip ratio & 0.817 (0.813 to 0.822$)$ & 0.817 (0.812 to 0.821$)$ & $0.816(0.811$ to 0.820$)$ & 0.821 (0.816 to 0.826$)$ & $0.003(-0.002$ to 0.007$)$ & 0.46 \\
\hline Ever smoked (\%) & $52.9(49.5$ to 56.3$)$ & 51.6 (48.1 to 55.0$)$ & 49.0 (45.6 to 52.5$)$ & 47.1 (43.7 to 50.0$)$ & 0.87 (0.77 to 0.99$)$ & 0.01 \\
\hline Current smokers (\%) & 14.3 (12.1 to 16.8$)$ & 10.7 (8.7 to 13.0) & 10.5 (8.6 to 12.8$)$ & $8.3(6.5$ to 10.4$)$ & 0.64 (0.52 to 0.79$)$ & $<0.001$ \\
\hline \multicolumn{7}{|l|}{ Non-manual social class (\%): } \\
\hline Adult & 40.5 (37.0 to 44.2$)$ & 48.3 (44.7 to 52.0$)$ & 50.5 (46.8 to 54.1$)$ & 46.3 (42.6 to 50.0$)$ & 1.14 (1.00 to 1.32$)$ & 0.02 \\
\hline Child & 20.6 (17.9 to 23.6$)$ & 21.3 (18.5 to 24.4$)$ & 23.3 (20.3 to 26.5$)$ & 24.4 (21.4 to 27.6$)$ & $1.18(1.00$ to 1.40$)$ & 0.05 \\
\hline
\end{tabular}

HOMA=homoeostasis model assessment score. HDLC=high density lipoprotein cholesterol. LDLc=low density lipoprotein cholesterol.

* Difference per kg of offspring birth weight: regression coefficients for continuous variables to odds ratios per kilogram of offspring birth weight for binary variables.

$\uparrow$ Geometric mean and logged regression coefficient.

₹ Doctor diagnosis of diabetes or fasting glucose $\geqslant 8 \mathrm{mmol} / \mathrm{l}$. 
ing birth weight of offspring (odds ratio 0.85 ; $95 \%$ confidence interval 0.71 to 1.00 ). For each $1 \mathrm{~kg}$ increase in birth weight, after adjustment for body mass index alone, the odds of high maternal insulin resistance fell by $27 \%$ (odds ratio $0.73 ; 0.60$ to 0.87 ), and there was no further change after full adjustment for a wide range of other potential confounders (systolic blood pressure, diastolic blood pressure, high density lipoprotein cholesterol, low density lipoprotein cholesterol, triglycerides, smoking status, adult social class, childhood social class). Because body mass index is positively related to insulin resistance (Pearson's correlation coefficient $0.43 ; 0.40$ to 0.46 ) and also to birth weight of offspring, it acts as an important negative confounder between birth weight of offspring and maternal insulin resistance. The fully adjusted regression coefficient for the insulin resistance log scores and the birth weight of offspring was -0.08 ( -12 to -0.04$)$ per kilogram of offspring birth weight, compared with -0.04 ( -0.08 to -0.01) per kilogram of offspring birth weight, for the coefficient adjusted for age. Adjustment for age and body mass index alone essentially produced the same findings as full adjustment $(-0.08 ;-0.13$ to -0.04$)$ per kilogram of offspring birth weight.

\section{Discussion}

Birth weight of offspring is inversely related to maternal insulin resistance in later life. This supports the fetal insulin hypothesis, which says that genetic factors related to both insulin resistance and birth weight explain at least part of the relation between birth weight and risk of adult cardiovascular disease and diabetes. $^{2}$

We expected birth weight of offspring to be positively associated with maternal insulin resistance in later life, since maternal gestational diabetes is associated with increased birth weight of offspring and also with maternal diabetes in later life. ${ }^{11}{ }^{15}$ Although the proportion of women with gestational diabetes may be insufficient to account for a population effect on the distribution of birth weight, there is evidence that gestational glycaemia across the population distribution (rather than a simple diabetic threshold effect) is positively associated with offspring birth weight and insulin resistance and frank diabetes in the mother in later life. ${ }^{1011}{ }^{16}$ Our results are contrary to this expectation and provide important support for the fetal insulin hypothesis. Definitive support of this hypothesis requires the identification of genes that are associated with both low birth weight and insulin resistance. Although there is some evidence for potential genes, further research is required in this area. ${ }^{2} 17$

\section{Limitations of the study}

Our response $(60 \%)$ is moderate but consistent with other baseline data collection in large epidemiological surveys, including that for the health survey for England, in which participants were visited at home. ${ }^{19}$ The mean cholesterol concentration, systolic blood pressure, smoking prevalence, and diabetes prevalence for women in our study are similar to those for older women in the health survey for England. ${ }^{19}$ The social class distribution of the British women's heart and health study is similar to that found for the 1991 census (52\% manual social class in the British women's

\section{What is already known on this topic}

Small birth weight is related to increased risk of cardiovascular disease and diabetes in adulthood; the underlying mechanisms are unclear

Small birth weight of offspring is related to parental cardiovascular disease, suggesting that common genetic factors affect birth weight and the risk of disease in adulthood

Genetic factors associated with the metabolism of insulin are plausible in linking birth weight and cardiovascular disease (the fetal insulin hypothesis)

What this study adds

Birth weight of offspring is inversely related to maternal insulin resistance in older age

Genetic factors related to both insulin resistance and birth weight explain at least part of the association between birth weight and risk of cardiovascular disease and diabetes in adulthood

heart and health study and $55 \%$ in older adults in the 1991 census). Response bias is, therefore, unlikely to have had an important effect on our results.

We have relied on maternal recall of offspring birth weight; this may be inaccurate. In one study of 649 children aged $6-15,75 \%$ of the birth weights that were recalled by parents were within $50 \mathrm{~g}$ of the hospital records. ${ }^{20}$ The mean age of the women in our study is 69 years, and the results from a study of parental recall of offspring birth weight of younger parents may not be applicable. Many of the women in our study will have had their firstborn offspring in the 1950s. Mean birth weights for boys and girls included in the 1958 British birth cohort are similar to those reported for offspring in our study (boys 3.40 (SD 0.45) $\mathrm{kg} v 3.38$ $(0.53) \mathrm{kg}$ in our study; girls, $3.26(0.43) \mathrm{kg} v 3.24(0.51)$ $\mathrm{kg}$ ) suggesting that maternal recall of offspring birth weight is unlikely to have importantly biased our results. ${ }^{21}$ The association between birth weight of offspring and insulin resistance in older age, rather than during the mothers' reproductive years, is more supportive of a genetic mechanism than a temporary hormonal effect of pregnancy on metabolic risk factors for cardiovascular disease. ${ }^{22}$

\section{Implications}

Our study provides epidemiological support for the fetal insulin hypothesis. This is important because it indicates that at least some of the association between the birth weight of individuals and their later risk of diabetes and cardiovascular disease may be genetic, and therefore not modifiable by interventions that influence intrauterine development. Future studies should aim to identify specific polymorphisms that are associated with low birth weight, insulin resistance, and cardiovascular disease.

The British women's heart and health study is codirected by Shah Ebrahim, Peter Whincup, Goya Wannamethee, and Debbie Lawlor. We thank Carol Bedford, Alison Emerton, Nicola Frecknall, Karen Jones, Mark Taylor, and Katherine Wornell for collecting and entering data, all of the general 
practitioners and their staff who have supported data collection and the women who have participated in the study

Contributors: All the authors developed the study aim and design. DAL undertook the initial analysis and coordinated writing of the paper. All authors contributed to the final version. DAL is guarantor.

Funding: The British women's heart and health study is funded by the Department of Health. DAL is funded by a Medical Research Council and Department of Health training fellowship. The views expressed in this publication are those of the authors and not necessarily those of the Department of Health or MRC.

Competing interests: None declared.

1 Barker DJP. Mothers, babies and health in later life. London: Churchill Livingstone, 1998.

2 Hattersley AT, Tooke JE. The fetal insulin hypothesis: an alternative explanation of the association of low birthweight with diabetes and vascular disease. Lancet 1999;353:1789-92.

3 Davey Smith G, Hart C, Ferrell C, Upton M, Hole D, Hawthorne V, et al. Birth weight of offspring and mortality in the Renfrew and Paisley study: prospective observational study. BMJ 1997;315:1189-93.

4 Davey Smith G, Harding S, Rosato M. Relation between infants' birth weight and mothers' mortality: prospective observational study. $B M J$ 2000;320:839-40.

5 Smith GC, Pell JP, Walsh D. Pregnancy complications and maternal risk of ischaemic heart disease: a retrospective cohort study of 129,290 births. Lancet 2001;357:2002-6.

6 Davey Smith G, Whitley E, Gissler M, Hemminki E. Birth dimensions of offspring, premature birth, and the mortality of mothers. Lancet 2000;356:2066-7.

7 Rasmussen F, Sterne J, Davey Smith G, Tynelius P, Leon DA. Fetal growth is associated with parents' cardiovascular mortality. Am I Epidemiol 2001;153(suppl):98S

8 Rasmussen F, Davey Smith G, Sterne J, Tynelius P, Leon DA. Birth characteristics of offspring and parental diabetes. Am J Epidemiol 2001;153(suppl):47S

9 Stoltenberg C, Magnus P, Bakketeig LS, Samuelsen SO, Leon DA, Davey Smith G. Infants' birth weight and parents' coronary heart mortality. Am J Epidemiol 2001;153(suppl):98S.
10 Scholl TO, Sowers M, Chen X, Lenders C. Maternal glucose concentration influences fetal growth, gestation, and pregnancy complications. Am J Epidemiol 2001;154:514-20.

11 Dornhorst A, Rossi M. Risk and prevention of type 2 diabetes in women with gestational diabetes. Diabetes Care 1998;21(suppl 2):43-9S

12 Shaper AG, Pocock SJ, Walker M, Cohen NM, Wale CJ, Thomson AG British regional heart study: cardiovascular risk factors in middle-aged men in 24 towns. BMJ 1981;283:179-86.

13 Lawlor DA, Bedford C, Taylor M, Ebrahim S. Geographic variation in cardiovascular disease, risk factors and their control in older women: British women's heart and health study. J Epidemiol Community Health (in press).

14 Matthews DR, Hosker JP, Rudenski AS, Naylor BA, Treacher DF, Turne RC. Homeostasis model assessment: insulin resistance and beta-cell function from fasting plasma glucose and insulin concentrations in man. Diabetologia 1985;28:412-9.

15 Pennison EH, Egerman RS. Perinatal outcomes in gestational diabetes: a comparison of criteria for diagnosis. Am J Obstet Gynecol 2001;184:1118 21.

16 Sermer M, Naylor CD, Gare DJ, Kenshole AB, Ritchie JW, Farine D, et al. Impact of increasing carbohydrate intolerance on maternal-fetal outcomes in 3637 women without gestational diabetes. Am J Obstet Gynecol 1995; 173:146-56.

17 Hattersley AT, Beards F, Ballantyne E, Appleton M, Harvey R, Ellard S. Mutations in the glucokinase gene of the fetus result in reduced birth weight. Nat Genet 1998;19:268-270.

18 Casteels K, Ong K, Phillips D, Bendall H, Pembrey M. Mitochondria 16189 variant, thinness at birth, and type-2 diabetes: ALSPAC study team: Avon longitudinal study of pregnancy and childhood. Lancet 1999;353:1499-500.

19 Erens B, Primatesta P. Health survey for England 1998: cardiovascular disease. London: Stationery Office, 1999.

20 O'Sullivan JJ, Pearce MS, Parker L. Parental recall of birth weight: how accurate is it? Arch Dis Child 2000;82:202-3.

21 Butler N, Alberman E. Perinatal problems: the second report of the 1958 British perinatal mortality survey. London: Livingstone, 1969.

22 Ness RB, Schotland HM, Flegal KM, Shofer FS. Reproductive history and coronary heart disease risk in women. Epidemiol Rev 1994;16:298-314.

(Accepted 28 March 2002) 